Editor's Note: These short, critical reviews of recent papers in the Journal, written exclusively by graduate students or postdoctoral fellows, are intended to summarize the important findings of the paper and provide additional insight and commentary. For more information on the format and purpose of the Journal Club, please see http://www.jneurosci.org/misc/ifa_features.shtml.

\title{
Converging Evidence for the Nogo-66 Receptor Gene in Schizophrenia
}

\author{
Aristotle N. Voineskos \\ Institute of Medical Science, School of Graduate Studies, and Department of Neuroscience, Centre for Addiction and Mental Health, University of Toronto, \\ Toronto, Ontario MST 1R8, Canada \\ Review of Budel et al. (http://www.jneurosci.org/cgi/content/full/28/49/13161)
}

Symptoms of schizophrenia likely arise from a failure of adequate communication between different brain regions and disruption of the underlying circuitry. Oligodendrocytes comprise the myelin sheath and create the basis for efficient information transfer throughout the human brain and CNS, by allowing rapid conduction of neural signals. Converging evidence from a variety of neuroscientific disciplines, such as electron microscopy, postmortem gene expression, animal models, gene association, and neuroimaging (diffusion tensor imaging in particular) has repeatedly pointed to myelin and oligodendrocyte abnormalities as a core feature of, and possible common pathway for, impaired connectivity in schizophrenia (Haroutunian and Davis, 2007). While several avenues of evidence are strong and lend impressive weight to the oligodendrocyte dysfunction hypothesis in schizophrenia, some weaknesses persist. In particular, genetic association studies of oligodendrocyte- and myelinrelated (OMR) genes have proven difficult to replicate, with some studies dem-

Received Jan. 28, 2009; revised March 8, 2009; accepted March 9, 2009.

This work was supported by Canadian Institutes of Health Research fellowship funding. I thank Dr. Fang Liu for her support and insight and Dr. James Kennedy, my PhD supervisor.

Correspondence should be addressed to Dr. Aristotle N. Voineskos, Institute of Medical Science, School of Graduate Studies, and Department of Neuroscience, Centre for Addiction and Mental Health, University of Toronto, 250 College Street, Room 708, Toronto, ON MST 1R8, Canada. E-mail: aristotle.voineskos@utoronto.ca.

DOI:10.1523/JNEUROSCI.0477-09.2009

Copyright $\odot$ 2009 Society for Neuroscience $\quad$ 0270-6474/09/295045-03\$15.00/0 onstrating no association of OMR genes with schizophrenia. Of the OMR gene polymorphisms that have demonstrated genetic association with schizophrenia, few have known functional consequences. Furthermore, the case for OMR gene involvement in schizophrenia suffers from a lack of convincing animal models.

In addition to speeding neuronal conduction, myelin plays an important role in inhibitory growth in the CNS, demonstrated in early seminal studies. A number of myelin-associated inhibitory growth factors have since been identified, including myelin-associated glycoprotein (MAG), oligodendrocyte-myelin glycoprotein (OMgp), and Nogo-A (RTN4). Despite their distinct molecular structures, OMgp, MAG, and RTN4 share a common axonal receptor, Nogo-66 receptor 1 (NgR1). Activation of NgR1 initiates a cascade that leads ultimately to inhibition of axonal growth. Given that it acts as a convergence point for three factors that inhibit neurite outgrowth and regeneration, NgR1 has generated much interest as a target for therapeutic intervention following CNS injury (Hsu et al., 2007). In addition to serving as a focus of study in CNS injury, NgR1 has also been investigated for a role in schizophrenia.

The NGR gene is located in the 22q11 region, a key susceptibility region in schizophrenia. A small number of gene association studies in schizophrenia have been performed for the NGR gene, with inconsistent evidence. Promisingly, rare nonconservative NGR sequence variants have been identified in schizophrenic cases only (Sinibaldi et al., 2004). However, a combined human and mouse genetic study showed no association with schizophrenia, and observed effects in the NGR deleted mouse were specific only to the motor domain (Hsu et al., 2007).

In a recent article published in The Journal of Neuroscience, Budel et al. (2008) provided converging evidence for a role for the Nogo-66 receptor in schizophrenia. The authors first performed a genetic association study for the Nogo-66 receptor gene with schizophrenia in three ethnically divergent samples. The authors then investigated the frequency of novel NGR variants in their Caucasian sample and performed detailed functional analyses of variants present only in individuals with schizophrenia. Finally, the authors examined mice lacking NgR1 to search for schizophrenia-associated phenotypes.

In the genetic association experiment, the authors examined seven singlenucleotide polymorphisms (SNPs) in the NGR gene. The SNPs were chosen to encompass genetic variation at the NGR locus. Genotyping of the NGR gene was performed in Caucasian, African-American, and Chinese Han samples, where both individual SNPs and haplotype combinations were analyzed (the authors obtained DNA from the Coriell Institute and the National Institute of Mental Health). Examination of each ethnic group separately can help reduce population stratification 
and affords the opportunity for replication across different populations. For their large sample of Chinese Han trios (i.e., parents and schizophrenic probands), the authors used a family-based association approach that is robust against population stratification. A small sample of African-American cases and controls was also examined. No association with schizophrenia was found in either sample, replicating previous negative findings in a Chinese population (Meng et al., 2007). It is unclear whether the African-American sample was sufficiently powered. In a Caucasian sample of schizophrenia cases and matched controls, the authors showed modest association (corrected for multiple comparisons) with schizophrenia for one haplotype [Budel et al. (2008), their Fig. 1], as well as for a modified additional haplotype. Budel et al. (2008) state that their finding in Caucasians replicates two previous studies, but one might argue that they strictly replicated one study (Liu et al., 2002), since the other study (Hsu et al., 2007) found no association with schizophrenia, after correction for multiple testing. Allele frequencies can vary dramatically within the Caucasian population and thereby produce an illusion of genetic homogeneity (Price et al., 2008). Budel et al. (2008) took the important step of verifying that their positive findings were not attributable to population stratification, by genotyping markers informative for admixture (i.e., the authors found no significant differences in genetic background of the Caucasian cases and controls). Overall, the association results for the NGR gene in these three ethnic groups was quite representative of many genetic studies in schizophrenia: both positive and negative findings occurred, and alleles that were positively associated were of small effect.

The authors next explored the possibility that rare coding variants exist in their schizophrenic population. While they did not find four previously described coding variants, the authors identified four novel nonconservative missense variants that were present only in the schizophrenic group [Budel et al. (2008), their Fig. 2A]. The authors proceeded to perform functional analysis of $\mathrm{NgR} 1$ variants in vitro. They showed that while NgR1 association with coreceptors p75-NTR, Taj/Troy, and Lingo-1 was unaltered in R377Q and R377W variants, signal transduction was altered. In R377substituted NgR1 [Budel et al. (2008), their Fig. 4C,D], both chick retinal explants and rat dorsal root ganglion neu- rons were incapable of transducing inhibitory myelin signals mediated by MAG. The authors concluded that R377Q and R377W substituted proteins blocked the function of $\mathrm{NgR} 1$ and functioned as dominant negatives [Budel et al. (2008), their Fig. $4 E$ ]. The authors also examined two NgR1 variants previously identified (R119W and R196H) (Sinibaldi et al., 2004), located in the ligand-binding domain of $\mathrm{NgR} 1$. To examine the functional consequences of these amino acid substitutions, the affinity of myelin ligands for the R119W-NgR1 and 196H-NgR1 proteins expressed in COS-7 cells were measured. The R199W substitution had selective effects on binding of some myelin ligands (MAG, OMgp), and the R196HNgR1 variant was incapable of mediating growth-cone collapse by myelin ligands (in E7 chick retinal neurons), thus indicating this substitution may abolish signal transduction without modulating the extent of protein-protein association [Budel et al. (2008), their Fig. 6]. Since this substitution did not affect binding affinity of myelin ligands for $\mathrm{NgR} 1$, it is possible that signal transduction was altered through a mechanism independent from NgR1 binding to myelin ligands. Despite this alternative explanation, these results provide strong evidence that four human NgR1 variants from schizophrenic individuals are functionally inactive in myelin-induced growth cone collapse assay, may possess dominant negative function in vitro, and may severely disrupt NgR1 signaling in individuals bearing these variants.

If inactivating sequence variants in human NGR contribute to increased schizophrenic risk, the authors hypothesized, mice lacking NgR1 might exhibit cognitive impairment characteristic of schizophrenia, such as working memory deficits. In a spatial delayed alternation task [Budel et al. (2008), their Fig. 7], a test of working memory, mice lacking NgR1 performed significantly worse than wild-type mice. Spatial learning and memory consolidation of NGR-deficient $(-/-)$ mice measured in the radial arm water maze, was not difference from that of wild-type mice $(+/+)$. Thus, the authors concluded that NGR-deficient mice exhibited impaired spatial working memory without widespread cognitive dysfunction. Prepulse inhibition (PPI) showed no consistent change in mice lacking NgR1. Although mice tested on the spatial delayed alternation task are sensitive to the dopamine $D_{1}$ receptor, NGR-deficient mice showed no dopaminergic change com- pared with wild-type mice. While the authors cited recent work supporting the role for $\mathrm{NgR} 1$ in regulating glutamatergic synaptic transmission, they did not investigate the glutamatergic system. It is notable that a very recent study of NGRdeficient mice found a significant genotype-by-treatment interaction in MK-801 (an NMDA channel blocker) treated mice in percentage of time moving, a locomotor activity measure. However, there were no cognitive differences, or PPI differences, in the mice of that study compared with wild-type mice (Hsu et al., 2007).

The major conclusion of the present study is that disrupted NgR1 function may increase susceptibility to developing schizophrenia. Yet, a stated goal in the CNS injury literature is to reduce or eliminate NgR1 function to achieve axon regeneration. Thus, one might think that reduced NgR1 function (potentially leading to axonal regeneration) may be effective for schizophrenia treatment given the cognitive impairment seen early in illness, and well described "soft" neurological signs observed in a sizeable minority of patients. However, the authors propose a model that insufficient myelin-mediated inhibition of neuritic sprouting may underlie failure to restrict anatomical plasticity in the brain, whereby risk for schizophrenia is increased. This model is consistent with the schizophrenia literature, given that studies show reduced oligodendrocyte number, and decreased OMR gene expression (Haroutunian and Davis, 2007), among other lines of evidence that suggest disrupted myelination in schizophrenia. Indeed, dysmyelinating disorders, particularly those affecting frontal and temporal regions, can produce a schizophrenia-like syndrome in late adolescence, that corresponds to typical time of onset in schizophrenia. It is possible that there is an optimal level of myelinmediated inhibition in normal neurodevelopment, associated with optimal cognitive performance, with the function characterized as an inverted U-shaped curve.

Critically important, in the study by Budel et al. (2008), was the attempt to establish functional significance of mutations in the NGR gene. The authors correctly point out that because these are rare NgR1 variants, biological tests of function, rather than genetic association statistics, provide an alternate and essential means to assess their role. By also demonstrating genetic association of the NGR gene in Caucasian schizophrenics, and 
showing that mice lacking NgR1 protein exhibit impaired spatial working memory, the authors provide an emerging picture implicating NgR1 in schizophrenia. With mounting evidence that rare genetic variation (Walsh et al., 2008) may contribute to schizophrenia, collaborative neuroscience approaches that focus on functional analysis and phenotypic characterization of such rare variations will likely be most useful for further elucidation of oligodendrocyte and myelin dysfunction in schizophrenia, along with other molecular pathways underlying this disorder.

\section{References}

Budel S, Padukkavidana T, Liu BP, Feng Z, Hu F, Johnson S, Lauren J, Park JH, McGee AW, Liao J, Stillman A, Kim JE, Yang BZ, Sodi S, Gelernter J, Zhao H, Hisama F, Arnsten AF, Strittmatter SM (2008) Genetic variants of
Nogo-66 receptor with possible association to schizophrenia block myelin inhibition of axon growth. J Neurosci 28:13161-13172.

Haroutunian V, Davis KL (2007) Introduction to the special section: myelin and oligodendrocyte abnormalities in schizophrenia. Int J Neuropsychopharmacol 10:499-502.

Hsu R, Woodroffe A, Lai WS, Cook MN, Mukai J, Dunning JP, Swanson DJ, Roos JL, Abecasis GR, Karayiorgou M, Gogos JA (2007) Nogo Receptor 1 (RTN4R) as a candidate gene for schizophrenia: analysis using human and mouse genetic approaches. PLoS ONE 2:e1234.

Liu H, Abecasis GR, Heath SC, Knowles A, Demars S, Chen YJ, Roos JL, Rapoport JL, Gogos JA, Karayiorgou M (2002) Genetic variation in the 22q11 locus and susceptibility to schizophrenia. Proc Natl Acad Sci USA 99:16859-16864.

Meng J, Shi Y, Zhao X, Guo S, Wang H, Zheng Y, Tang R, Feng G, Gu N, Liu H, Zhu S, He L (2007) No association between the genetic polymorphisms in the RTN4R gene and schizophrenia in the Chinese population. J Neural Transm 114:249-254.

Price AL, Butler J, Patterson N, Capelli C, Pascali VL, Scarnicci F, Ruiz-Linares A, Groop L, Saetta AA, Korkolopoulou P, Seligsohn U, Waliszewska A, Schirmer C, Ardlie K, Ramos A, Nemesh J, Arbeitman L, Goldstein DB, Reich D, Hirschhorn JN (2008) Discerning the ancestry of European Americans in genetic association studies. PLoS Genet 4:e236.

Sinibaldi L, De Luca A, Bellacchio E, Conti E, Pasini A, Paloscia C, Spalletta G, Caltagirone C, Pizzuti A, Dallapiccola B (2004) Mutations of the Nogo-66 receptor (RTN4R) gene in schizophrenia. Hum Mutat 24:534-535.

Walsh T, McClellan JM, McCarthy SE, Addington AM, Pierce SB, Cooper GM, Nord AS, Kusenda M, Malhotra D, Bhandari A, Stray SM, Rippey CF, Roccanova P, Makarov V, Lakshmi B, Findling RL, Sikich L, Stromberg T, Merriman B, Gogtay N, et al. (2008) Rare structural variants disrupt multiple genes in neurodevelopmental pathways in schizophrenia. Science 320:539-543. 